\title{
The health system response to Eltor cholera outbreak: an experience in Iran
}

\author{
Ghomian Z, PhD ${ }^{1}$, Yousef Nezhad S, MSc ${ }^{2 *}$, Jahangiri K, $\mathrm{PhD}^{3}$, Khodadadizadeh A, MSc ${ }^{4}$ \\ 1- Assistant Prof., Dept. of Health in Emergencies and Disaster, School of Health, Safety and Environment, Shahid Beheshti \\ University of Medical Sciences, Tehran, Iran. 2- PhD Candidate, Dept. of Health in Emergencies and Disaster, School of \\ Health, Safety and Environment, Shahid Beheshti University of Medical Sciences, Tehran, Iran. 3- Associate Prof., Dept. of \\ Health in Emergencies and Disaster, School of Health, Safety and Environment, Shahid Beheshti University of Medical \\ Sciences, Tehran, Iran. 4- Faculty Member, Dept. of Nursing, School of Nursing and Midwifery Sciences, Rafsanjan \\ University of Medical Sciences, Rafsanjan, Iran.
}

\begin{abstract}
Received: July 2016, Accepted: October 2016

Background: Following the outbreak of eltor cholera in Iraq's Kurdistan, Iran was threatened through the western border. Therefore, the aim of the present study was to evaluate the health system response of Marivan city in Kurdistan Province (Iran) as a risky gateway for the outbreak of eltor cholera epidemic in Iran.

Materials and Methods: This cross-sectional study was implemented in Marivan in October 2012 in 6 steps with different methods of data gathering including situation analysis, and document and literature review. Case finding is important in controlling disease outbreak. We mention to case finding in the health system.in Marivan city.

Results: During the Eltor epidemic in Marivan, Control measures, training actions, and coordination measures had been within and outside the organization such as the health system, municipality, police, industries, mine and trade, terminals and transportation, local radio, agriculture, and water and sewerage. To create an intersectional coordination for disease control, job description of the offices was issued by the governor to them, and the health system response was appropriate and timely in controlling the Eltor epidemic.

Conclusions: After the outbreak of Eltor in Iraq and following the announcement of standby status by Iran's Ministry of Health and Medical Education (MOHME), the health system of Marivan took steps to deal with the Eltor epidemic. We proposed the improvement of control measures and organizational coordination to control the probable outbreak. The appropriate strategies were presented to improve the performance of the health system and treatment in similar situations.
\end{abstract}

Keywords: Epidemic, Cholera, Outbreak, Health Care System, Response

\section{Introduction}

Eltor cholera is a potential epidemic disease that is under the surveillance system of Iran's Ministry of Health and Medical Education (MOHME) and should be reported immediately. This bacterial disease is caused by Vibrio cholera (1). V. cholera is defined as endemic in Iran. In most cases, the disease was reported in patients coming from the eastern borders of the country. Such outbreaks were reported in the provinces of Sistan and Baluchestan, Khorasan, Kerman, and Golestan (Iran) (2).
In the National Health Care System of Iran, various measures are taken for the immediate detection and prevention of the occurrence and spread of epidemic diseases, in particular eltor cholera. Among infectious diseases, the prevention and control of this disease has found a high priority $(3,4)$.

Eltor cholera has affected many individuals and has negative social, economic, and

\footnotetext{
* Corresponding author: Sadegh Yousef Nezhad, Dept. of Health in Emergencies and Disaster, School of Health, Safety and Environment, Shahid Beheshti University of Medical Sciences, Tehran, Iran.

Email: yusefnejad785@yahoo.com
} 
political consequences; therefore, it is expected that the health care system at all levels be prepared for its prevention and control $(5,6)$. Therefore, planning as a function of preparedness phase in the outbreak management cycle is very important to effective response to and controlling of the situation $(7,8)$.

In October 2012, after the eltor cholera outbreak in Iraq's Kurdistan, Iran's MOHME announced an emergency situation in cities, including Marivan, at the western borders. This study was performed to evaluate the health system response to the eltor cholera epidemic in the city of Marivan.

\section{Materials and Methods}

Marivan city is located in Kurdistan Province in the west of Iran. The city is boarded by Saghez from the north, Sanandaj from the east and southeast, Paveh from the south, and Iraq's Kurdistan from the west and northwest. According to the population census in 2011, the city's total population was estimated to be 168,774 . This city is the third most crowded city in the province.

A common border with Iraq's Kurdistan, and the transition of many people, especially the people of Iran's and Iraq's Kurdistan, through the western borderline named Bashmaq, has made the transmission of eltor cholera to the country possible. Considering the eltor cholera outbreak in Kurdistan of Iraq, on the border of the city of Marivan, control measures were taken and internal and external coordination was implemented to control its outbreak.

This cross-sectional study was implemented in Marivan in October 2012 in 6 steps with different methods of data gathering, including situation analysis, and document and literature review.

The study was conducted in 6 steps. First, literature review, including guidelines and related documents on eltor cholera, was conducted and an online search was performed with keywords of eltor, disaster, response, epidemic, crisis, man-made, and biological disaster. Second, situation analysis was conducted, including investigation of the situation of eltor cholera infection in Marivan and examination of the follow-up forms that were routinely completed in health centers. Third, the measures of the health centers, existing reports, and investigator's observations were evaluated and the information obtained in the three previous steps was categorized. Fourth, the individuals responsible for or involved in incident management in Marivan Health Center and Kurdistan Health Center were interviewed. Fifth, response measures for the eltor cholera outbreak in Marivan were analyzed. Sixth, appropriate strategies were developed to improve the performance of health centers in similar cases.

\section{Results}

\section{Brief description of case finding}

First case (index case): A man who had 26 years of age and was a resident of Marivan working as a building contractor in Iraq's Kurdistan, had mild symptoms of diarrhea in 2012/9/25 in Iraq's Kurdistan and had returned to Marivan in 2012/10/2. He was admitted to the emergency ward of the hospital in Marivan in 2012/10/4, and due to being suspected of having eltor, stool examination was performed on him. The samples were sent to the laboratory in 2012/10/5 and the first case of eltor was diagnosed. The medical history of the patient showed that he was taking antacid medications prescribed by a gastroenterologist. $\mathrm{He}$ had gone from Sanandaj (capital of Kurdistan Province) to Tehran in 2012/10/8, and after visiting a physician, he had returned to Sanandaj and then to Marivan.

The second case of eltor: A man, who had 31 years of age, was self-employed, and had traveled to Iraq's Kurdistan in 2012/9/29, had watery diarrhea (he had eaten restaurant food and had used water in tankers and vegetables). $\mathrm{He}$ had returned to Iran from Iraq in 2012/10/5. Then, he had been admitted to the hospital and physicians had performed 
symptomatic treatment for him, and then, discharged him. The physician had conducted a stool examination for him on the same day and had diagnosed him as a positive case in 2012/10/9.

After reporting of the two positive cases, an assessment team, including experts on disease control and environmental health, had referred to patients' homes for follow-up. The first case was not at home; he had gone to Tehran due to gastrointestinal disease. Health experts had checked the rate of residual chlorine in household water. The second case was also not at home when the health experts had gone to visit him. He had returned home with a phone call by his wife. Health experts had checked the rate of residual chlorine in the household water and the patient had been brought to the health center. Tests were again conducted on him and he was prescribed medication based on a country protocol, and then, the epidemiological investigation form for confirmed cases was completed.

The third case of this disease was identified in 2012/10/9 and the forth case in 2012/10/10.

In $2012 / 10 / 11,5$ other cases were identified. From among the total 9 cases diagnosed, 5 had traveled to Iraq's Kurdistan. The total number of patients diagnosed was 19 .

A total of 1341 rectal swab samples were collected during the eltor epidemic (2012/10/4-2012/11/14). Before the eltor epidemic, 233 samples were collected due to surveillance of water and food-borne diseases. During 2012/10/11 to 2012/11/8 no patients had been diagnosed with eltor. Therefore, the date of 2012/11/14 was reported as the end of the emergency situation and control of eltor epidemic in Marivan.

Emergency meeting of the Eltor Committee of Marivan was held with partnership of and at health centers in 2012/10/9. The decisions of the meeting include:

- Follow-up of patients by health center staff, completion of the epidemiological form for patients, and their treatment
- Follow-up of the 2 patients with acute watery diarrhea referred to health centers; follow-up of their treatment and tests and reporting them to Kurdistan Health Center

- Follow-up with the trajectory of the operational team, visiting of border villages, and completion of the epidemiological survey form.

- Visiting the villages with water supply system problems, discussing it in the committee, reporting to the rural water and wastewater department, and performing reforms

- Mapping epidemiology of the reported diarrheal cases and confirmed patients

- Drawing the map of drinking water sources in Marivan and reporting to committee members

- Preparation of an isolation room in hospitals

- Making placards of "information base of Eltor" in both Kurdish and Farsi

- Visiting of hospitals by health experts for correction of defects related to registration and sending samples to the laboratory

- Determining two health workers to follow up with the sampling, suspected cases, and hospital samples

- Visiting the border health surveillance unit and eltor information base daily, completing the patients list of patients with confirmed eltor, and registering them in the portal of the MOHMET's center for diseases control

- Registration of the addresses of patients and sampling cases with diarrhea

- Training of personnel about necessary actions and reporting suspected cases to health centers

- Collection, controlling, and registration of the samples in health centers and hospitals

- Meeting with physicians for justification of the implementation of 
treatment for patients according to the country protocol

- Creation of emergency plans by health centers and follow-up of suspected cases

- Follow-up and assessment of confirmed patients and consultation with them in this regard

\section{Discussion}

Since the beginning, a crisis must be responded to. The purpose of response is conducting interventions and measures during and after the phase of disaster occurrence to reduce human and financial losses. To achieve the intended goal, it is necessary to coordinate between organizations and individuals based on job description, responsibilities, authority, regulation, and recourses $(9,10)$.

The health system has an important role in responding to disasters and emergencies, because health is most important factor for individuals. The health system should prepare to confront disasters and emergencies because relying on resources and facilities of other regions or expecting to receive health facilities in other regions result in the loss of the vital time to prevent the crisis and increased mortality and human suffering (11).

Western provinces of Iran, due to their common border with Iraq, are susceptible to the incidence of different kinds of diseases especially water and food-borne diseases such as eltor. Factors such as insufficiency of safe drinking water, lack of water piping, lack of health systems and sewage disposal, diversity in provision and distribution of drinking water, poor health status of Iraq, and the simplicity of crossing the border increase the probability of disease outbreaks especially oral-fecal diseases such as eltor. Therefore, the risk of the transmission of eltor to Iran via the west border is notable (12).

After occurrence of the eltor epidemic in Iraq and warning due to its spreading to Iran, the health system of Marivan took the necessary actions to control it. Planning, coordination with other organizations, provision of job description for responsible organizations in response to the crisis, and provision of necessary facilities for diagnosis and treatment of patients were the strengths of the control plan of the health system of Marivan in the eltor epidemic.

The response to the eltor epidemic had two goals of decreasing mortality, and preventing the occurrence of new cases. The health system of Marivan prevented the spreading of the disease and the incidence of new cases through health education and suitable response to the eltor epidemic.

The most important action at the beginning of the response during diagnosis of the first case of eltor was defining responsibility at different levels, especially the health system of Marivan; personnel who had been trained respond to the eltor epidemic were assigned to determining responsibility. As soon as the occurrence of the eltor epidemic was confirmed in Marivan, the committee of epidemic control was held there. Since the disease outbreak had occurred at the border of Iran and Iraq, a joint border committee was necessary for the coordination of activities between the countries, but this measure was not taken.

At first, the eltor committee held meetings daily, but due to the suitable response to crisis and the prevention of its spreading to other region based on surveillance data they were held weekly. During meetings, members of the committee reviewed designated responsibilities based on the framework program and they made sure of the improvement of planning for epidemic control. Suspected cases were reported instantly. The health system reported mortality rate and new cases daily, although it had reported zero mortality and zero new cases, because reporting is necessary for the surveillance system.

The risk of eltor occurrence through the western border of the country is significant due to the factors previously mentioned (12). Activities were performed through disaster 
control approach, while the risk assessment approach can lead to valuable results. The following items are the weaknesses of these measures:

- Lack of definition of the Incident Command System (ICS) in the health center

- Lack of exercise to prepare for similar events that will lead to inconsistency between teams Therefore, in order to improve performance and increase preparedness in case of a crisis, the following can be considered as the proposed strategy:

- Developing policies, operational manuals, and guidelines at a national level

- Planning and determining the resources and local management structure

- Increasing knowledge, and improving attitudes and skills at the individual level

- Situational analysis

- Community hazards identification

- Designing an Incident Command System (ICS)

- Providing an updated information system and monitoring system

- Designing and developing an early warning system

- Providing resources and equipment based on type of risk

- Continuous education and exercises

- Involving all managers at various levels in the process of planning

- Making a commitment to implement programs

- Changing approaches from logistic to risk reduction and development planning in the community

- Holding a joint border committee between the states involved to establish coordinated activities

\section{Conclusion}

After the eltor cholera outbreak in Iraq's Kurdistan, Iran's MOHMET announced an emergency situation in the cities at the western border including Marivan. Therefore, some actions were carried out in Marivan such as planning, coordination with other organizations, especially the water and sewages organization in order to check the system and provide them with a job description at time of disasters, and procurement of equipment and supplies needed to diagnose and treat diseases. These activities were performed through disaster control approach, while the risk assessment approach can lead to valuable results.

\section{Acknowledgments}

We appreciate and thank experts in centers for disease control and prevention of the health system of Marivan especially Mr. Borhan Akhtar and Mrs. Shahnaz Ghaderi.

Conflict of Interest: None declared

\section{References}

1. Mandell GL, Bennett JE, Dolin R. Mandell, Douglas, and Bennett's Principles and Practice of Infectious Diseases. $7^{\text {th }}$ ed. London: Churchill Livingstone; 2009. P.2536-44. (Vol 2).

2. Heymann DL. Control of communicable disease manual. $19^{\text {th }}$ ed. Washington, DC: American Public Health Association; 2008. P.100-8.

3. Faruque SM, Sack DA, Sack RB, Colwell RR, Takeda Y, Nair GB. Emergence and evolution of vibrio cholerae 0139. Proc Natl Acad Sci U S A 2003; 100(3):1304-9.

4. Global Task Force on Cholera Control. Cholera outbreak: assessing the outbreak response and improving preparedness. World Health Organization, Geneva; 2010 Nov. 87 p. Report No.: WHO/CDS/CPE/ZFK/2004.4

5. Gotuzzo E, Cieza I, Estremadoyrol, Seas C. Cholera: lessons from the epidemic in Peru. Infec Dis Clin North Am 1994; 8(1):183-205.

6. Zahraei SM, Afshari Naghdeh MT, Najafabadi MS, Maesoomiasl H, Javanmard A, Safari MH. The epidemic of cholera in Iran in 2005. Irannian Journal of Infectious Diseases 2007; 12(36):1-4.

7. Khazaei HA, Rezaei N, Bagheri GR, Moin AA. A six year study on vibrio cholerae in southern Iran. Jap J Infect Dis 2005; 58:8-10.

8. Barati HA, Golmohmmadi A, Momeni I, Moradi G. A cholera outbreak investigation in karaj district in 2008. Iranian Journal of Epidemiology 2010; 6(3):28-34.

9. Eshrati B, Rezaei Ashtiani A, Khazaei F, Torkamani F,Azimi M. The association of a 
number of risk factors with the cholera outbreak of Markazi province 2005. Iranian Journal of Epidemiology 2007; 3(1):47-51.

10. Jahangiri K. Principles and Foundations of Crisis Management in Industries. $2^{\text {nd }}$ ed. Tehran: Institute of Higher Education ScientificApplied Helal Iran; 2012.

11. Khankeh H. Hospital preparedness in the Accidents \& Disasters (country program). $1^{\text {st }}$ ed.
Tehran: University of Social Welfare and Rehabilitation; 2014.

12. Rahbar M, Sabourian R, Saremi M, Abbasi M, Masoomi Asl H, Soroush M. Epidemiological and drug resistant pattern of vibrio cholera $\mathrm{O} 1$ biotype Eltor serotype Inaba during the summer of 2005 outbreak in Iran. Journal of Ardabil University of Medical Science 2007; 7(1):41-5. 